\title{
Definition of the rectum and level of the peritoneal reflection - still a matter of debate?
}

\author{
Jakub Kenig, Piotr Richter \\ $3^{\text {rd }}$ Department of General Surgery, Jagiellonian University Medical College, Krakow, Poland
}

Videosurgery Miniinv 2013; 8 (3): 183-186

DOI: 10.5114/wiitm.2011.34205

\begin{abstract}
Introduction: Pathological lesions of the rectum are common and their management requires detailed knowledge of pelvic anatomy. There has been considerable debate as to the definition of the rectum and the variability of the level of the peritoneal reflection. The lack of a clear consensus was proven in the research by McCullen et al. regarding the current pattern of practice for the investigation of primary rectal cancer by general surgeons.

Aim: To carry out bibliographic research on the definition of the rectum and level of the peritoneal reflection.

Material and methods: A web-based published literature search of PubMed, Ovid Medline, Science Direct and Springer was made.

Results: The paper presents the current definitions of proximal and distal margin of the rectum and level of peritoneal reflection based not only on the results of tests on cadavers but also on living humans.

Conclusions: The results of tests on living humans allow more accurate qualification of patients for local excision, which is particularly important for patients with colorectal cancer.
\end{abstract}

Key words: definition of the rectum, level of peritoneal reflection, anatomy of the rectum.

\section{Introduction}

Pathological lesions of the rectum are common and their management requires detailed knowledge of pelvic anatomy. With the introduction of minimally invasive surgical techniques (transanal endoscopic microsurgery, endoscopic mucosal resection, endoscopic submucosal dissection, laparoscopy) the detailed preoperative diagnosis is of great importance for the choice of treatment modality. There has been considerable debate as to the definition of the rectum, its length, and the site of transition from sigmoid to rectum. The lack of a clear consensus was recently proven by the research of McCullen et al., who examined the current pattern of practice for the investigation of primary rectal cancer by general sur- geons. Among 124 surgeons there was considerable variation in the definitions of proximal and distal boundaries of the rectum. Sixty-seven percent of respondents defined the upper boundary of the rectum as an anatomic landmark (35\% the peritoneal reflection, $21 \%$ the rectosigmoid junction, $12 \%$ the coalescence of taeniae) and 30\% defined it as a given distance from the anal verge (3\% 20-25 cm, 24\% 12$19 \mathrm{~cm}, 3 \% 8-11 \mathrm{~cm})$. Seventy-six percent of respondents provided an anatomic landmark for the distal boundary of the rectum (43\% anal verge, 19\% dentate line and $15 \%$ anal canal), whereas the remaining $23 \%$ did not, describing the rectum as anything below their definition of the upper boundary [1]. Proper location of the anatomical landmarks (among 
others peritoneal reflection, promontory) is also essential in qualifying patients for transanal endoscopic microsurgery or neoadjuvant radiotherapy.

\section{Aim}

That is why the aim of the study was to carry out bibliographic research on the definition of the rectum, in accordance with evidence-based medicine.

\section{Material and methods}

A web-based published literature search of PubMed, Ovid Medline, Science Direct and Springer was made. The main search terms were "definition of the rectum", "length of the rectum", "laparoscopic anatomy of the rectum", "radiological anatomy of the rectum", "endoscopic anatomy of the rectum", and "surgical planes and landmarks of the rectum". Only papers with a high impact factor addressing the subject matter were considered, although no publications were systematically excluded.

\section{Results}

The rectum is an 18- to $20-\mathrm{cm}$ long part of the large intestine, located between the sigma and the anal canal. It is located to the front of the sacrum, and passes through the pelvic diaphragm that separates the rectum into the pelvic and anal part. The shape of the rectum is in lower mammals straight. That is why the word rectum comes from Latin "rectus" meaning straight. However, in humans, the rectum has curves adapting to the shape of the sacrum and coccyx bone [2]. Moreover, the rectum exhibits lateral curves (usually three: two on the left side and one on the right), which correspond on the intraluminal aspect to Houston's valves - superior $(9-10 \mathrm{~cm}$ from the anal verge); the middle valve, termed KohIrausch's valve, which is the most consistent $(6-8 \mathrm{~cm}$ from the anal verge); and inferior (4-5 cm from the anal verge) $[3,4]$. The rectum can be divided into three parts: the upper, middle, and lower rectum. From the anal verge, these three parts are defined as follows: the lower rectum, 0 to $6 \mathrm{~cm}$; the middle rectum, 7 to $11 \mathrm{~cm}$; and the upper rectum, 12 to $15 \mathrm{~cm}$ [5-7]. In most of the surgical and anatomical books the most useful landmark for the transition from the sigmoid colon to the rectum is the loss of the taenia coli, the appendices epiploicae and the surgical mesocolon at about the level of the third sacral vertebra at the rectosigmoid junction, where the superior rectal artery and a couple of the hypogastric nerves enter the pelvic cavity. Most parts of the rectum are extraperitoneal, although the upper third is covered anteriorly and laterally by the peritoneum to the peritoneal reflection $[8,9]$. Anatomical boundaries differ from rectal surgical borders. From an anatomical standpoint, the rectal sigmoid transition is located at the third sacral vertebra S3, and surgery is to limit the amount of promontory. The rectal passage of the anal canal is the height of the dentate line and surgically is located at the level of the levator ani muscle $[3,10]$.

The National Cancer Institute Rectal Cancer Focus Group defined the rectum as anything up to $12 \mathrm{~cm}$ from the anal verge. The idea is that the anatomic rectum may travel up to $15 \mathrm{~cm}$ or $16 \mathrm{~cm}$, but that these proximal tumors behave like sigmoid cancers in regard to recurrence pattern and prognosis.

Another essential anatomical structure, especially for the treatment of lesions using transanal microsurgery, is the peritoneal reflection. If the tumor is located above the peritoneal reflection, then the danger of injury to the bowel is increased with opening of the peritoneal reflection. However, the location and length of the peritoneal reflection are highly variable. Buess et al., describing their TEM technique, defined the length of the peritoneal reflection as up to $12 \mathrm{~cm}$ anteriorly, $15 \mathrm{~cm}$ laterally, and $20 \mathrm{~cm}$ posteriorly, but he did not specify the methods of measurement [11, 12]. There are some studies measuring the length of the peritoneal reflection as the proximal limit of the rectum but all of them have one very important limitation. All the measurements were performed in cadavers, so there was a difference to the rectum lengths of live humans. Some surgical books propose the anatomic reference of the second rectal valve as the location of the anterior peritoneal reflection, which should be approximately $8 \mathrm{~cm}$ and $6 \mathrm{~cm}$ from the anal verge in men and women, respectively $[2,13]$.

Gerdes et al. used transrectal ultrasound in locating the site of the peritoneal reflection in relation to rectal lesions in live humans. Although it was possible to visualize all the anatomical structures using ultrasound, they did not include specific measurements of the distance from the anal verge to the peritoneal reflection [14].

Najarian et al. also determined the position of the peritoneal reflection in living patients. The mean lengths of the peritoneal reflection were $9 \mathrm{~cm}$ anteriorly, $12.2 \mathrm{~cm}$ laterally, and $14.8 \mathrm{~cm}$ posteriorly for 
females, and $9.7 \mathrm{~cm}$ anteriorly, $12.8 \mathrm{~cm}$ laterally, and $15.5 \mathrm{~cm}$ posteriorly for males. The lengths of the anterior, lateral, and posterior peritoneal measurements were statistically different from one another, regardless of gender $(p<0.01)$. According to the authors, the peritoneal reflection is located higher on the rectum than reported in autopsy studies. Moreover, there was no difference between males and females [15].

A unique study was performed by Yun et al. which measured the pelvic anatomy in detail. The mean lengths of the sacral promontory were $16.5 \pm 2.2 \mathrm{~cm}$ and $16.1 \pm 2.2 \mathrm{~cm}$ in males and females, respectively. As for the peritoneal reflection, the results were anterior $(8.8 \pm 2.2 \mathrm{~cm}, 8.1 \pm 1.7 \mathrm{~cm})$, lateral $(10.8 \pm 2.7 \mathrm{~cm}$, $11.4 \pm 1.9 \mathrm{~cm})$ and posterior $(13.8 \pm 2.5 \mathrm{~cm}, 14.0 \pm 1.9 \mathrm{~cm})$, respectively. There were no statistically significant differences between males and females. The height of the patient had a correlation with the length of the sacral promontory both in males and females $(p<0.05)$. For all the estimated lengths, the length of the sacral promontory had a statistically significant correlation with the lengths of the anterior and posterior peritoneal reflection. Based on the measurements, the authors created a formula that predicts the level of essential pelvic structures (from the anal verge) using height of the patient.

- For males:

- Length of sacral promontory $(\mathrm{cm})=-10.0+0.2$ $\times$ height $(\mathrm{cm})$,

- Length of anterior peritoneal reflection $(\mathrm{cm})=$ $-9.7+0.1 \times$ height $(\mathrm{cm})$

- For females:

- Length of sacral promontory $(\mathrm{cm})=-5.1+0.1 \times$ height $(\mathrm{cm})$,

- Length of anterior peritoneal reflection $(\mathrm{cm})=$ $-6.3+0.1 \times$ height $(\mathrm{cm})$.

In the authors' opinion, the level of the sacral promontory is most applicable to the definition of the upper border of the rectum from both the radiotherapeutic and clinical standpoint [16]. Furthermore, the formula allows for more accurate qualification of patients for transanal endoscopic operations (especially in borderline patients).

Sadahiro et al. measured the length of different parts of the large colon after barium enema in $920 \mathrm{Ja}$ panese patients. However, they did not measure any specific distances of pelvic structures apart from the length of the rectum, which was $16.96 \pm 1.59 \mathrm{~cm}$ in males and $17.62 \pm 1.69 \mathrm{~cm}$ in females (the difference was statistically significant; $p<0.01$ ) [17].

Torkzad et al. in their study on morphometric assessment with magnetic resonance imaging found that the rectum does not begin at the level of the sacral promontory in the supine position. In all studied patients the mesorectum and rectum began at least $10 \mathrm{~mm}$ below S1-2. As the authors say, this can lead, at least theoretically, to overtreatment of the patients having the radiation field above the level of the sacral promontory (as is the standard in the case of neoadjuvant radiotherapy of rectal cancer). Of course, the mentioned limitation of the study was the small number of patients and to suggest something a study on a larger number of patients must be conducted [18].

Taken together, one of the most important factors is the level of the peritoneal reflection from the surgical standpoint. We show the results of published studies in living humans regarding the distance of the peritoneal reflection from the anal verge in Table I.

\section{Conclusions}

The length of the rectum and the peritoneal reflection are important parameters from the surgical standpoint. Their preoperative determination may lead to more accurate surgical qualification for endoscopic local excision, especially in the case of rectal cancer.

Table I. Distance of the peritoneal reflection from the anal verge in living humans

\begin{tabular}{|lcccc|}
\hline Study (year) & No. of patients & \multicolumn{3}{c|}{ Distance of peritoneal reflection [cm] } \\
\cline { 3 - 5 } & & Anterior & Lateral & Posterior \\
\hline Najarian et al. (2004) & 50 & F: $9(5.5-13.5)$ & F: 12.2 (8.5-17) & F: 14.8 (11-19) \\
\cline { 2 - 4 } & & M: $9.7(7-16)$ & M: $12.8(9-19)$ & M: 15.5 (12-20) \\
\hline Yun et al. (2008) & 46 & M: 8.8 \pm 2.2 & M: $10.8 \pm 2.7$ & M: 13.8 \pm 2.5 \\
\hline
\end{tabular}




\section{References}

1. McMullen TPW, Easson AM, Cohen Z. The investigation of primary rectal cancer by surgeons: current pattern of practice. Can J Surg 2005; 48: 19-26.

2. Dujovny N, Quiros RM, Saclarides TJ. Anorectal anatomy and embryology. Surg Oncol Clin N Am 2004; 13: 277-93.

3. Skawina A. Anatomy [Polish]. Publishing of Jagiellonian Univeristy, Krakow 2006.

4. Jorge JM, Wexner SD. Anatomy and physiology of the rectum and anus. Eur J Surg 1997; 163: 723-31.

5. Salerno G, Sinnatambi C, Branagan G, et al. Defining the rectum: surgically, radiologically and anatomically. Colorectal Dis 2006; 8: 5-9.

6. Skrovina M, Soumarova R, Kycina R. Anastomotic leakage after laparoscopic total mesorectal excision for low rectal cancer. Videosurgery Miniinv 2011; 6: 5-11.

7. Sýkora R, Krhut J, Jonszta T. Fistula between anterior rectum wall and seminal vesicles as a rare complication of low-anterior resection of the rectum. Videosurgery Miniinv 2012; 7: 63-6.

8. Heald RJ, Moran BJ. Embryology and anatomy of the rectum. Semin Surg Oncol 1998; 15: 66-71.

9. Gołębiewski A, Murawski M, Łosin M. Laparoscopic surgical technique to facilitate management of high anorectal malformations - report of seven cases. Videosurgery Miniinv 2011; 6: 150-4.

10. Wałecka J, Pokora W, Śmietański M. Perineal hernia - different surgical approaches and treatment techniques. A case report. Videosurgery Miniinv 2011; 6: 37-41.

11. Buess G, Mentges B, Manncke K, et al. Technique and results of transanal endoscopic microsurgery in early rectal. Am J Surg 1992; 163: 63-9.

12. Michalik M, Bobowicz M, Frask S, et al. Transumbilical laparoendoscopic single-site total mesorectal excision for rectal carcinoma. Videosurgery Miniinv 2012; 7: 118-21.

13. Beck DE, Wexner SD. Fundamentals of anorectal surgery. McGraw-Hill, New York 1992.

14. Gerdes B, Langer P, Kopp I, et al. Localization of the peritoneal reflection in the pelvis by endorectal ultrasound. Surg Endosc 1998; 12: 1401-4.

15. Najarian MM, Belzer GE, Cogbill TH, et al. Determination of the peritoneal reflection using intraoperative proctoscopy. Dis Colon Rectum 2004; 47: 2080-5.

16. Yun HR, Chun HK, Lee WS, et al. Intra-operative measurement of surgical lengths of the rectum and the peritoneal reflection in Korean. J Korean Med Sci 2008; 23: 999-1004.

17. Sadahiro S, Ohmura T, Yamada Y, et al. Analysis of length and surface area of each segment of the large intestine according to age, sex and physique. Surg Radiol Anat 1992, 14: 251-7.

18. Torkzad MR, Blomqvist L. The mesorectum: morphometric assessment with magnetic resonance imaging. Eur Radiol 2005; 15: 1184-91.

Received: 1.01.2013, accepted: 19.02.2013. 